\title{
PENGUJIAN EFEKTIVITAS DIURETIK KOMBINASI EKSTRAK ETANOL DAUN AFRIKA (Gymnanthemum amygdalinum Del.) DAN DAUN KELAPA SAWIT (Elaeis guineensis Jacq.) PADA TIKUS JANTAN
}

\author{
Delisma Simorangkir, Wahyudi, Rani Junimar, Puji Lestari, Nina \\ Irmayanti Harahap \\ Fakultas Farmasi Institut Kesehatan Deli Husada Deli Tua \\ e-mail :simorangkirdelisma@gmail.com
}

\begin{abstract}
African leaf and palm leaf have a secondary metabolite content such as alkaloids and flavonoids that are efficacious as diuretics. The purpose of this study is to know the effectiveness of diuretics from the combination african leaf ethanol extract and palm leaf ethanol extract. Methods used Eksperiemental. Diuretic test divided into six treatment. Each group consists of 3 tails of white rats. Group 1 (positive control) administered Furosemide $3.6 \mathrm{mg} / \mathrm{kgBB}$, Group 2 (negative control) was given suspension $\mathrm{Na}-\mathrm{CMC} 0.5 \%$, group 3 without treatment as well as groups of 4.5, and 6 in a row administered a combination of African leaf extract doses and extracts Oil palm leaf ethanol in a row of "50 $\mathrm{mg} / \mathrm{kgBB}+67$, $5 \mathrm{mg} / \mathrm{kgBB} " ;$ "100mg/kgBB + $135 \mathrm{mg} / \mathrm{kgBB} " ;$ and "200 mg/kgBB + $270 \mathrm{mg} / \mathrm{kgBB}$ ". Each mouse gave $20 \mathrm{ml} \mathrm{NaCl} / \mathrm{kgBB}$ as an oral loading dose. Measured urine volume is recorded every hour for 6 hours. The results showed that the combination of African leaf ethanol extract dosage and palm leaf ethanol extract had a diuretic effect if it was compared with negative control. The results showed that the combination of African leaf extract $200 \mathrm{mg} / \mathrm{kgBB}+$ palm leaves 270 $\mathrm{mg} / \mathrm{kgBB}$ was the most effective dose of 6 groups, because it produced the highest urine volume of $23.01 \mathrm{ml}$.
\end{abstract}

Keywords: Diuretic, Gymnanthemum amygdalinum Del., Elaeis guineensis Jacq.

\section{PENDAHULUAN}

Edema adalah akumulasi cairan serosa yang terlokalisasi di dalam sel dan jaringan tubuh yang menyebabkan peningkatan tekanan hidrostatik kapiler dan peningkatan volume plasma yang ditandai dengan pembengkakan di dalam atau di bawah kulit. Jika daerah yang bengkak itu merah dan panas kemungkinan ada infeksi. Kondisi ini dapat disebabkan oleh trauma, pengobatan dan penyakit sistemik (King, 2017; Trayes, 2013). Edema akan terjadi pada hipoproteinemia, hipertensi dan gagal ginjal yang parah seperti GGK (Thomas \& Tanya, 2012). Dalam mengatasi edema keamanan tanaman herbal lebih baik dibandingkan dengan obat diuretik (Chandrasekar, 2017). 
Diuretik adalah obat yang dapat meningkatkan output urin dan ekskresi elektrolit yang bekerja pada nefron dan berguna untuk pengobatan edema, gagal ginjal kronik dan hipertensi sedang dan keracunan (Aziz, 2014). Diuretik juga merupakan landasan dalam penanganan gagal jantung kongestif (Chittuni \& Novask, 2018). Efek diuretik pada suatu senyawa dapat merangsang pengeluaran urin. Senyawa diuretik dapat mempengaruhi secara lansung transpor zat terlarut dan air melalui ginjal (Darmono, 2011 ; Permadi, 2016).

Daun afrika (Gymnanthemum amygdalinum Del) dan kelapa sawit (Elaeis guineensis Jacq.) banyak ditemukan di Indonesia dan hampir di setiap daerah. Ekstrak etanol daun afrika dapat menurunkan kadar kolesterol pada tikus dengan dosis efektif $100 \mathrm{mg} / \mathrm{KgBB}$ (Noberston, 2018). Daun kelapa sawit sangat bermanpaat antara lain sebagai pakan ternak, dan kerajinan tangan.

Penelitian sebelumnya bahwa ekstrak etanol daun afrika dan pada dosis $100 \mathrm{mg} / \mathrm{kgBB}$ dibandingkan dengan furosemid menunjukkan peningkatan volume urin dalam waktu 6 jam terhadap tikus putih jantan (Olufunso dan Tope, 2014). Kombinasi Furesemid dengan daun afrika dapat meningkatkan volume urine pada tikus dengan dosis efektif $40 \mathrm{mg} / \mathrm{kg}$ BB (Warouw, 2020).

Minyak sawit dapat berguna sebagai anodyne, anti dotum, afrodisiak, dan diuretik (Owoyele, 2015). Salah satu kandungan fitokimia dari kelapa sawit adalah senyawa fenolik yaitu flavonoid, tannin, kumarin, alkaloid, saponin, terpenoid, steroid dan karbohidrat (Lounini, 2012).

\section{MetOde PENELITIAN Pengambilan Sampel}

Sampel yang digunakan pada penelitian ini adalah daun afrika dan daun kelapa sawit yang berasal dari desa sungai pinang, kecamatan tambang, kabupaten kampar, propinsi riau.

\section{Pembuatan Simplisia Daun Afrika Dan Daun Kelapa Sawit}

Sampel daun afrika dan daun kelapa sawit ditimbang dengan berat masing-masing sampel sebanyak $6 \mathrm{~kg}$ yang sudah dipisahkan langsung dari batang dan rantingnya. Daun afrika dan daun kelapa sawit yang segar dicuci bersih, kemudian dirajang kecilkecil dan dikeringkan dan diperoleh berat kering $3 \mathrm{~kg}$. Daun tersebut dinyatakan kering bila telah tampak berwarna coklat dan dapat dipatahkan. Kemudian diserbukan dengan cara diblender hingga diperoleh berat serbuk daun afrika dan daun kelapa sawit $1,5 \mathrm{~kg}$.

\section{Pembuatan Ekstrak}

Dalam penelitian ini pembuatan ekstrak dilakukan dengan cara maserasi yaitu menggunakan pelarut etanol $96 \%$, yaitu sebanyak $500 \mathrm{~g}$ simplisia serbuk dimasukkan kedalam wadah 
kaca kemudian dituangi cairan penyari sebanyak $3,75 \mathrm{~L}$ sampai simplisia terendam semua dan ditutup, dibiarkan selama 3 hari terlindung dari cahaya dan diadukaduk kemudian disaring, ampasnya dimaserasi dengan $1,25 \mathrm{~L}$ etanol $96 \%$ disimpan dalam wadah tertutup baik di tempat sejuk yang terlindung dari cahaya matahari selama 2 hari, kemudian dienaptuangkan. Hasil penyarian yang diperoleh kemudian diuapkan dengan menggunakan rotary evaporator $\pm 40^{\circ} \mathrm{C}$ kemudian dipekatkan.

\section{Pembuatan suspensi Na-CMC $0,5 \%$}

Dalam lumpang ditaburkan sebanyak 0,5 g CMC-Na pada lumpang yang telah berisi air suling panas. Kemudian didiamkan selama 15 menit lalu digerus homogen hingga massa yang transparan, lalu diencerkan dengan air suling, dicampur sampai homogenkan dan dimasukkan ke dalam labu tentukur kemudian ditambahkan volumenya sampai $100 \mathrm{~mL}$ dengan air suling.

\section{Pembuatan suspensi furosemid}

Furosemid pada tikus yakni $3,6 \mathrm{mg} / \mathrm{kgbb}$, nilai ini diperoleh dari konversi dosis furosemid pada manusia dewasa yaitu 40 mg, jika dikonversikan pada tikus dengan berat badan $200 \mathrm{~g}$ adalah $0,018 \mathrm{~g} / 200 \mathrm{gBB}$. Jumlah furosemid yang akan diinduksi pada tikus dihitung berdasarkan berat badan dari masing-masing tikus yang dilarutkan dalam Na-CMC 0,5\%.

\section{Pembuatan Suspensi Kombinasi Ekstrak Etanol Daun Afika (EEDA) Dan Ekstrak Etanol Daun Kelapa Sawit (EEDKS)}

EEDA dan EEDKS dibuat suspensi dengan Na-CMC 0,5\% dengan dosis yang berbeda, pada dosis kombinasi EEDA dan EEDKS untuk dosis pertama EEDA 50 $\mathrm{mg} / \mathrm{kgbb}+67,5 \mathrm{mg} / \mathrm{kgbb}$ EEDKS, dosis kedua EEDA $100 \mathrm{mg} / \mathrm{kgbb}+$ $135 \mathrm{mg} / \mathrm{kgbb}$ EEDKS, dosis ketiga EEDA $200 \mathrm{mg} / \mathrm{kgbb}+270 \mathrm{mg} / \mathrm{kgbb}$ EEDKS. Dosis ekstrak yang telah ditimbang kemudian dicampurkan dengan Na-CMC 0,5\% sampai homogen hingga volume $10 \mathrm{ml}$.

\section{Prosedur Uji Efek Diuretik}

Hewan yang digunakan sebanyak 18 ekor tikus jantan dimana kemudian dibagi 6 kelompok, tiap kelompok terdiri dari 3 ekor tikus. Tikus dipuasakan dengan cara tidak diberi makanan selama \pm 8 jam tetapi diberi minum, selanjutnya ditimbang bobot tikus. Kemudian tikus diberi $\mathrm{NaCl} 0,9 \%$ dengan dosis $20 \mathrm{~mL} / \mathrm{kg}$ BB secara oral. Setiap ekor tikus diberi perlakuan yang dibagi 6 kelompok yaitu :

kelompok I : kontrol posistif diberikan furosemid 3,6 mg/kgbb.

Kelompok II : kontrol negatif diberikan CMC-Na 0,5\%, Kelompok III : tanpa pengobatan kelompok IV pemberian dosis kombinasi EEDA dan EEDKS dengan dosis pertama EEDA $50 \mathrm{mg} / \mathrm{kgbb}+$ $67,5 \mathrm{mg} / \mathrm{kgbb}$ EEDKS. 
Kelompok $\mathrm{V}$ : dosis ke dua EEDA $100 \mathrm{mg} / \mathrm{kgbb}+135 \mathrm{mg} / \mathrm{kgbb}$ EEDKSKELOMPOK VI : dosis ketiga EEDA $200 \mathrm{mg} / \mathrm{kgbb}+270 \mathrm{mg} / \mathrm{kgbb}$ EEDKS. Masing-masing tikus dimasukkan ke dalam kandang metabolik yang telah dimodifikasi. Volume urin yang diekskresikan dicatat pada jam ke-1,2,3,4,5 dan 6 selama 6 jam.

\section{Analisis Data}

Analisis data dalam penelitian ini menggunakan program SPSS 18.0. Data dianalisis dengan uji ANOVA untuk menentukan perbedaan rata-rata diantara kelompok, apabila ada perbedaan maka akan dilanjutkan dengan uji Post Hoc Tukey HSD dengan tujuan melihat perbedaan nyata antar kelompok perlakuan.

\section{HASIL PENELITIAN}

Tabel 1. Daun Afrika

\begin{tabular}{cccc}
\hline No & $\begin{array}{l}\text { Identifika } \\
\text { si }\end{array}$ & Ekstrak & $\begin{array}{l}\text { Simplisi } \\
\text { a }\end{array}$ \\
\hline 1 & Flavonoid & $(+)$ & $(+)$ \\
2 & Alkaloid & $(+)$ & $(+)$ \\
3 & Saponin & $(+)$ & $(+)$ \\
4 & Tanin & $(+)$ & $(+)$ \\
5 & Steroid & $(+)$ & $(+)$ \\
\hline
\end{tabular}

Tabel 2. Daun Kelapa Sawit

\begin{tabular}{cccc}
\hline No & $\begin{array}{c}\text { Identifik } \\
\text { asi }\end{array}$ & Ekstrak & Simplisi \\
& & $a$
\end{tabular}

\begin{tabular}{llll}
\hline 1 & $\begin{array}{c}\text { Flavonoi } \\
\mathrm{d}\end{array}$ & $(+)$ & $(+)$ \\
& Alkaloid & $(+)$ & $(+)$
\end{tabular}

$\begin{array}{cccc}3 & \text { Saponin } & (+) & (+) \\ 4 & \text { Tanin } & (+) & (+) \\ 5 & \text { Steroid } & (+) & (+)\end{array}$

Keterangan :

$(+)$ positif $=$ mengandung golongan senyawa

(-) negatif $=$ tidak mengandung golongan senyawa

Tabel 3. Hasil Pengukuran Volume Urin Tikus Rata-Rata Setiap Jam dalam durasi waktu Selama durasi 6 Jam.

\begin{tabular}{|c|c|c|c|c|c|c|c|}
\hline \multirow{2}{*}{$\begin{array}{l}\text { Kelompok } \\
\text { pengujian }\end{array}$} & \multirow{2}{*}{$\begin{array}{c}\text { Volume } 30 \\
\text { menit }\end{array}$} & \multicolumn{6}{|c|}{ Rata-rata volume urin setiap jam (ml) } \\
\hline & & 1 jam & $2 \mathrm{jam}$ & 3 jam & 4 jam & 5 jam & 6 jam \\
\hline $\begin{array}{l}\text { Furosemid } 40 \\
\mathrm{mg} / \mathrm{kgbb}\end{array}$ & 0,71 & 1,06 & 1.13 & 1,49 & 1,59 & 1,53 & 1,54 \\
\hline CMC Na $0,5 \%$ & 0,71 & 0,90 & 0,99 & 0,95 & 0,96 & 0,96 & 0,97 \\
\hline Tanpa Pengobatan & 0,71 & 0.92 & 1.04 & 0.94 & 0.92 & 0.93 & 0.89 \\
\hline $\begin{array}{l}\text { EEDA Dosis } 50 \\
\text { mgkgkb +EEDKS } \\
67.5 \mathrm{mg} / \mathrm{kgbb}\end{array}$ & 0,74 & 1,03 & 1.21 & 1,22 & 1,24 & 1,24 & 1.25 \\
\hline $\begin{array}{l}\text { EEDA Dosis } 100 \\
\text { mgkgbb +EEDKS } \\
135 \text { makobb }\end{array}$ & 0,74 & 1,07 & 1,18 & 1.27 & 1,28 & 1,28 & 1,29 \\
\hline $\begin{array}{l}\text { EEDA Dosis } 200 \\
\text { mgkgobb +EEDKS } \\
270 \text { mgkgbb }\end{array}$ & 0,71 & 1,09 & 1,17 & 1,35 & 1,35 & 1,35 & 1,36 \\
\hline
\end{tabular}

Gambar 1. Volume Total Urin Pada Tikus Jantan

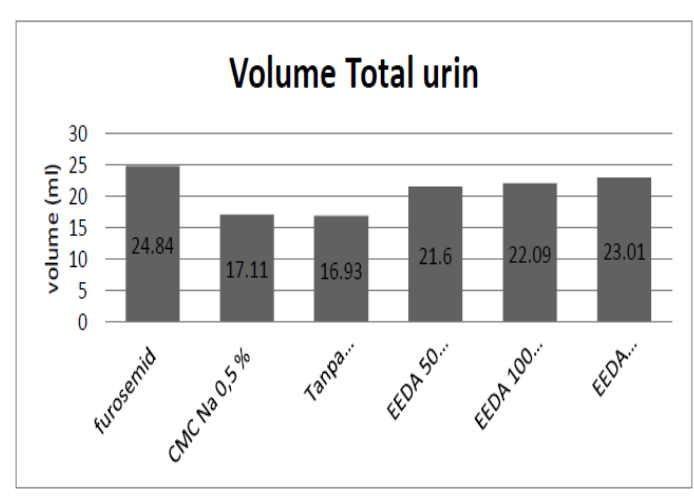

\section{PEMBAHASAN}

Salah satu parameter pada penelitian ini, adalah volume urin. Volume urin dapat meningkat penggunaan diuretik karena dapat menyebabkan diuresis. 
Penambahan volume urin yang banyak juga mempengaruhi jumlah pengeluaran zat-zat terlarut dalam urin. Pengukuran volume urin dilakukan dengan mengukur volume urin rata - rata setiap jam dan mengukur volume urin total selama 6 jam pada masing-masing kelompok.

Pada Gambar 1 menunjukkan bahwa jam ke-6 semua sediaan uji menunjukkan efek diuretik demikian juga dengan kelompok pembanding. EEDA+EEDKS dengan dosis $200 \mathrm{mg} / \mathrm{kgbb}+270 \mathrm{mg} / \mathrm{kgbb}$ menunjukkan efek yang paling banyak dalam pengeluaran urin. Peningkatan volume urine dapat dilihat pada jam ke-2, dimana EEDA+EEDKS dengan dosis 200 $\mathrm{mg} / \mathrm{kgbb}+270 \mathrm{mg} / \mathrm{kgbb}$ ini menimbulkan pengeluaran urine tidak jauh berbeda dengan

\section{KESIMPULAN}

Berdasarkan hasil penelitian yang diperoleh dapat disimpulkan bahwa kombinasi ekstrak etanol daun afrika (EEDA) dan ekstrak etanol daun kelapa sawit (EEDKS) memiliki efek diuretik pada tikus jantan. Konsentrasi kombinasi EEDA dan EEDKS yang lebih efektif sebagai diuretik adalah kombinsi EEDA dosis $200 \mathrm{mg} / \mathrm{kgbb}$ +EEDKS $270 \mathrm{mg} / \mathrm{kgbb}$.

\section{DAFTAR PUSTAKA}

Assogba, F.M., Chouaibou, A., Wilfrid, A., Mansourou, M., Joachim, D. (2015) evaluation of diuretik propertiesfrom furosemid dosis $40 \mathrm{mg} / \mathrm{kgbb}$ tetapi pada jam ke 4-6 dosis furosemide $40 \mathrm{mg} / \mathrm{kgbb}$ mengalami peningkatan pengeluaran urin yang lebih signifikan dibandingkan sediaan uji. Menurut Saad Ali (2018), furosemide memiliki waktu paruh 2 jam dengan pemberian peroral onset 45-60 menit dan dapat bertahan 5-7 jam. Pada EEDA+EEDKS dengan dosis 100 $\mathrm{mg} / \mathrm{kgbb}+135 \mathrm{mg} / \mathrm{kgbb}$ dengan EEDA+EEDKS pada dosis $50 \mathrm{mg} / \mathrm{kg}$ $\mathrm{bb}+67,5 \mathrm{mg} / \mathrm{kgbb}$ dapat memberikan efek dalam pengeluaran urin pada jam ke-4, dan EEDA+EEDKS dengan dosis 50 $\mathrm{mg} / \mathrm{kgbb}+67,5 \quad \mathrm{mg} / \mathrm{kgbb}$ yang mempunyai efek diuretik paling rendah dibandingkan dengan EEDA+EEDKS pada dosis 100 $\mathrm{mg} / \mathrm{kg} \quad \mathrm{bb}+135 \mathrm{mg} / \mathrm{kgbb}$ dan EEDA+EEDKS pada dosis 200 $\mathrm{mg} / \mathrm{kg} \quad \mathrm{bb}+270 \quad \mathrm{mg} / \mathrm{kgbb}$.

Elaeis guineensis jacg. (Aracaceae) leaves agueous extrctin wistar rat. Journal of Cheminal and Pharmaceutical Research. 7(3):2457-2462.

Aziz, M. dkk. (2014). Phytochemical Screening and Evaluation of the Diuretic Activity of Aqueous Methanol Extract from Aerial Parts of Mentha viridis Linn (Labiatae) in Albino Rats. Tropical Journal of Pharmaceutical Research. 13 (7): 1121-1125

Chandrasekar \& Sivagami. B. (2017) Indian Medicinal Plants With Diuretic Activity. Indo 
American Journal of Pharmaceutical Research. ISSN NO: 2231-6876.

Chittuni, C. \& Novask, J. (2018). Diuretic In The Management of Cardiorenal Syndrome. National Kidney Foundation. 25 (5), P425-433.

Darmono, Syamsudin. (2011). Farmakologi eksperiemental. Jakarta: Penerbit Universitas Indonesia. Halaman 110.

King, M. (2017). Management Of Edema. The journal of clinical and anaestecy dermatology. 10(1): E1-E4.

Nessa. (2013). Efek Diuretik dan Daya Larut Batu Ginjal dari Ekstrak Etanol Rambut Jagung (Zea mays L.). Journal. Fakultas Farmasi, Universitas Andalas. Padang.

Noberston. (2018). Uji Efektivitas Ekstrak Etanol Daun Afrika Terhadap Kadar Kolesterol Total Tikus Putih Model Hiperkolesterolemia-Diabetes. Farmakologika jurnal farmasi volume 15 No. 2.

Owoyele, B, Owolabi, G. (2014). Taditional oil palm (Elaeis guineensis jacg.) and its medicinal uses: A Review. Tang Humanitas Medicine. 4 (3).
Olufunso, Odewusi.O. \& Tope (2015). An assessment of the diuretic effect of Vernonia amygdalinaaqueous extract on wistar rats. Central European Journal of Experimental Biology, 4(2):11-16.

Permadi, A. (2006). Tanaman Obat Pelancar Air Seni. Cetakan I. Jakarta: Penebar Swadaya. Halaman 16-20.

Saad, A. (2018). Pharmacological Parameters Study On Loop Diuretic Drug - Furesemide. Journal Of Formulation Science \& Bioavailability. 2 (1). 117.

Tanu, I. (2009). Farmakologi dan Terapi Edisi 5. Jakarta: Balai Penerbit FKUI. Halaman 40.

Thomas, J \& Tanya. M. (2012). Pemeriksaan Fisik dan Keterampilan Praktis. Jakarta:EGC.

Trayes, K et. All. (2013). Edema: Diagnosis and Management. American Family Physician 1. 88 (2).

Warouw, V. Pareta, D. Mongie, J. Paat, V. (2020). Uji Efektivitas Diuretik Ekstrak Daun Afrika Vernonia amygdalina pada Tikus Putih Jantan Rattus norvegicus. Jurnal Biofarmasetikal Tropis, 3 (1) : 122-127. 